\title{
O TERMO INICIAL DA VIDA HUMANA DEPENDENTE E SUA CONSEQUENTE PROTEÇÃO PENAL NO DELITO DE ABORTO
}

\author{
Gisele Mendes de Carvalho ${ }^{1}$ \\ Fernanda Diniz Aires ${ }^{2}$
}

\begin{abstract}
Resumo: O objetivo do presente artigo é delimitar com precisão o termo inicial da proteção da vida humana dependente (tipo objetivo do delito de aborto) e, para tanto, utiliza-se o método predominantemente dedutivo e teórico, por meio da análise da jurisprudência e da revisão bibliográfica de diversos periódicos, livros e trabalhos publicados sobre o tema. A delimitação ontológica do início da vida e o consequente marco axiológico de sua proteção legal são importantes porque, no ano de 2016, a Primeira Turma do Supremo Tribunal Federal julgou o Habeas Corpus $n^{\circ} 124.306 / 2016$, oportunidade em que, sob a escusa de uma interpretação conforme a Constituição, considerou atípico o aborto praticado até o terceiro mês de gestação. Busca-se assim provar que essa decisão deve ser considerada inconvencional, além de uma apropriação pelo Poder Judiciário de matéria de competência e legitimidade do Poder Legislativo, violando o princípio da separação dos poderes e da legalidade do direito penal.
\end{abstract}

Palavras-chave: Vida humana dependente; Tutela penal; Aborto; Nidação; Controle de Constitucionalidade.

\section{INTRODUÇÃO}

O direito fundamental à vida (de forma geral) suscita debates tanto no que se refere ao início da proteção à vida e ao direito de morrer (aborto e eutanásia), em especial com relação ao primeiro quando confrontado com novas questões relativas ao controle do ser humano sobre sua própria reprodução.

\footnotetext{
${ }^{1}$ Pesquisadora do CNPq. Mestre em Direito pela Universidade Estadual de Maringá, Doutora e Pós-Doutorado em Direito Penal pela Universidade de Zaragoza, Espanha. Professora Associada de Direito Penal da Universidade Estadual de Maringá (UEM). Professora do Mestrado Profissional em Políticas Públicas da Universidade Estadual de Maringá. Atual Coordenadora da Especialização em Ciências Penais da Universidade Estadual de Maringá. Atual Diretora Adjunta do Centro de Ciências Sociais Aplicadas da Universidade Estadual de Maringá (mandato 2016-2020). Centro Universitário de Maringá (UNICESUMAR), Paraná. Brasil. E-mail: giselemendesdecarvalho@yahoo.es

${ }^{2}$ Mestre pelo Programa de Pós-Graduação em Ciências Jurídicas pela UNICESUMAR e pós-graduanda em MBA em Administração Pública e Gerência de Cidades. Graduada pela Universidade Estadual de Maringá (UEM). Recebeu láurea acadêmica. Pós-graduada (2014/2015) em Direito Tributário e Gestão Tributária pelo Instituto de Direito Constitucional e Cidadania (IDCC) em parceria com a Universidade Estadual do Norte do Paraná (UENP). Atua na área de direitos da personalidade e biodireito. Centro Universitário de Maringá (UNICESUMAR), Paraná. Brasil. E-mail: ferdinizaires@gmail.com
} 
Contudo, no direito brasileiro, o legislador já realizou essa valoração, tipificando atentados contra a vida humana dependente por meio do delito de aborto. Portanto, a vida humana intrauterina, apesar de encontrar-se vinculada ao corpo materno e dele depender para seu desenvolvimento, possui proteção autônoma. Desse modo, é necessário delimitar com precisão o termo inicial dessa proteção (tipo objetivo do delito de aborto). Isso porque o tema ganhou relevância com a relativização da proteção penal pelo poder judiciário, quando o Supremo Tribunal Federal, em uma decisão não definitiva e sem efeito vinculante ou erga omnes, considerou atípica a interrupção da gestação até o terceiro mês, a partir de argumentos socioeconômicos e de política criminal.

O objetivo desse trabalho é a análise da tutela da vida humana dependente ou pré-natal, a partir de um exame da realidade empírica do bem jurídico tutelado, em sua perspectiva físicobiológica, e dos princípios da dogmática penal. Foi utilizado o método predominantemente dedutivo e teórico, por meio da análise da jurisprudência e da revisão bibliográfica de diversos periódicos, livros e trabalhos publicados sobre o tema.

\section{O ESTATUTO JURÍDICO DA VIDA INTRAUTERINA}

Nesse artigo, como já afirmado, o direito à vida será analisado a partir de uma perspectiva jurídica e como um direito individual de primeira geração (ainda que seja possível considerar que a vida permeie todas as gerações ou dimensões de direitos) $)^{3}$.

Com objetivo de estabelecer os limites da tutela penal no ordenamento jurídico brasileiro e o substrato do bem jurídico, a vida humana intrauterina será considerada em sua projeção ou existência físico-biológica. Contudo, é válido deixar claro que ela vai muito além desse aspecto, que por razões metodológicas, as questões sociais e históricas não serão aqui tratadas ${ }^{4}$.

3 “As primeiras, correspondem os direitos de liberdade, ou um não-agir do Estado; aos segundos, os direitos sociais, ou uma ação positiva do Estado. Embora as exigências de direitos possam estar dispostas cronologicamente em diversas fases ou gerações, suas espécies são sempre - com relação aos poderes constituídos, apenas duas: ou impedir os malefícios de tais poderes ou obter seus benefícios. Nos direitos de terceira e de quarta geração, podem existir direitos tanto de uma quanto de outra espécie”. (BOBBIO, 2004, p. 9).

4 Sobre a gerações de direitos fundamentais: "Enfim, se nos deparam direitos da primeira, da segunda e da terceira gerações, a saber, direitos da liberdade, da igualdade e da fraternidade, conforme tem sido largamente assinalado, com inteira propriedade, por abalizados juristas. Haja vista a esse respeito a lição de Karel Vasak na aula inaugural de 1979 do Curso do Instituto Internacional dos Direitos do Homem, em Estrasburgo [...]. Os direitos de primeira geração são os direitos da liberdade, os primeiros a constarem do instrumento normativo constitucional, a saber direitos civis e políticos, que em grande parte correspondem, por um prisma histórico, àquela fase inaugural do constitucionalismo do Ocidente." (BONAVIDES, 2004, p. 562). 
Além disso, essa perspectiva biológica (como um processo natural) exclui do direito à vida em sentido estrito todas questões históricas e contingentes que permitiriam a classificações/relativizações culturais e subjugação de vidas como carentes de valor vital, como já se chegou a preconizar ${ }^{5}$. A pretensão de tratar o direito à vida sob essa perspectiva deve-se ao fato que a concretização normativa precisa garantir pelo menos o mínimo fundamental, sem perder de vista que a pessoa é unitária e transcende quaisquer universos culturais (GONÇALVES, 2008, p. 95).

A primeira característica do direito à vida que é ele existe "desde que" e "enquanto" a mesma existe, isso significa dizer que a titularidade desse direito só pode ser exercida do começo ao final da vida humana. Portanto, quando se tutela a vida e se exige esse direito, é no sentido de continuar existindo e continuar vivendo, com o objetivo de manter todas as condições necessárias para que seja possível a sua continuação (CASABONA, 1994, p. 27). Porquanto esse direito é o mais fundamental de todos os direitos, tendo em vista que é supedâneo para o exercício de quaisquer outros. Isto porque, não faria sentido o poder constituinte declarar e reconhecer nenhum direito sem que antes fosse assegurado o direito de estar vivo para usufruí-lo.

Portanto, trata-se do primeiro centro ou dever de tutela, pois refere-se a própria realidade subsistente do ser humano. Isto porque o direito à vida faz parte do conjunto de aspectos fundamentais mínimos que garante a existência do indivíduo como ente-pessoa em concreto, ou seja, trata-se do substrato essencial, sem o qual não há que se falar em pessoa ${ }^{6}$.

A Constituição Federal, em seu artigo $5^{\circ}$, caput, assegura a todos brasileiros e estrangeiros residentes no país, a inviolabilidade do direito à vida (BRASIL, 1988). Essa proteção foi complementada com a ratificação e incorporação da Convenção Interamericana de Direitos Humanos (artigo 4.1) ao ordenamento jurídico brasileiro (BRASIL, 1992), tendo em vista que o Estado brasileiro se obrigou a preservar a vida humana em geral desde a concepção.

Portanto, o direito à vida é uma exigência individual, oposta em face do Estado, que não pode dispor da vida dos indivíduos, ainda que em face de interesses coletivos (status negativo),

5 Nesse mesmo sentido: "La concepción do direito a la vida en estos términos, impone ya varias acotaciones necessárias: em primer lugar, al entenderlo em um sentido naturalístico, esto es, al decirnos que se proyecta sobre una realidade físico-biológica, se excluyen del concepto de su objeto cualesquiera valoraciones sociales que pudieran indicar qué es vida humana y qué no lo es, aunque no estén excluidas determinadas valoraciones para estabelecer la mayor o menor intensidade de su protección por el Derecho (p.ej., la condición de Jefe de Estado, y otras que veremos em el capítulo V); em segundo lugar, no importa el estado, condición y capacidade concretas de prestación social de ese indivíduo, ni la calidad, racionalidad ou viabilidade de esa vida: las vidas carentes de valor vital, como em algún momento histórico se llegó a preconizar." (CASABONA, 1994, p. 25-26).

6 "Deste centro de tutela derivam direitos de personalidade, como sejam o próprio direito à vida e à integridade física, e também o direito a uma autonomia moral e jurídica, consequências e reflexo da própria e radica autonomia ôntica de um sujeito subsistente... e talvez nenhum mais.” (GONÇALVES, 2008, p. 95). 
bem como tem o dever de atuar positivamente para proteção social de cada vida humana (status positivo) ${ }^{7}$. Assim, a previsão constitucional e convencional, explicitamente garantistas, geram um dever jurídico do Estado e dos particulares. Portanto, há um direito de todo ser humano de não sofrer atentados contra a sua vida, em contrapartida há um dever geral de não matar. Ainda, pode-se dizer que o direito à vida impõe ao indivíduo uma série de outros deveres com relação à proteção da sua própria vida e da vida dos outros. Diante disso, é possível distinguir três grupos de titulares de direitos e deveres: o Estado, que tem o dever de proteção e de abstenção (respeito) com relação aos particulares, o próprio indivíduo com relação à sua vida e as demais pessoas (CASABONA, 1994, p. 29).

O desenvolvimento da vida humana tem início com a fecundação, ainda que a proteção se dê em momento diferente, e termina com a morte. Essa proteção se amplia com o nascimento quando o crime contra a vida deixa de ser tipificado como aborto, cedendo lugar ao homicídio ou infanticídio ${ }^{8}$.

O objetivo desse trabalho é a análise da tutela da vida humana dependente ou pré-natal. Diante disso, é imprescindível a exame da realidade empírica ${ }^{9}$ do bem jurídico tutelado ${ }^{10}$, bem

7 "Com efeito, na medida em que os direitos fundamentais exprimem os valores nucleares de uma ordem jurídica democrática, seus efeitos não podem se resumir à limitação jurídica do poder estatal. Os valores que tais direitos encarnam devem se irradiar por todos os campos do ordenamento jurídico, impulsionando e orientando a atuação do Legislativo, Executivo e Judiciário. Os direitos fundamentais, mesmo aqueles de matriz liberal, deixam de ser apenas limites do Estado, convertendo-se em norte de atuação." (SARMENTO, 2004, p. 134).

8 “A relevância jurídica da precisão do início da vida humana independente é manifesta, já que a partir desse instante opera-se uma modificação nas valorações jurídico penais do injusto e da culpabilidade, em razão da existência de uma vida autenticamente autônoma. A mudança da qualidade jurídica do objeto da ação é decisiva para qualificação jurídico- penal do fato como homicídio ou como o aborto. Assim, até o início do nascimento, qualquer pessoa que atente contra o nascituro incidirá nas penas do delito de aborto, por se tratar o bem jurídico em questão de vida humana dependente, ainda subordinada à vida da mãe. Com as dores do parto e das contrações de dilatação, tem início a vida humana independente, bem jurídico do delito de homicídio. [...].” (CARVALHO, 2001, p. 106).

9 “O bem jurídico- ponto central da estrutura do delito- constitui, antes de tudo, uma realidade válida em si mesma, cujo conteúdo axiológico não depende do juízo do legislado (dado social preexistente). Contrariamente ao proposto por Binding, a norma não cria o bem jurídico, mas sim o encontra. Daí o seu aspecto restritivo. Isso porque o fim do direito não é outro que de proteger os interesses do homem, e estes preexistem à intervenção normativa, não podem ser de modo algum criação ou elaboração jurídica mas se impõe a ela." (PRADO, 2004, p. 30).

10 Sobre o conceito de bem jurídico: "De outro lado, o bem jurídico vem a ser um ente (dado ou valor social) material ou imaterial haurido do contexto social, de titularidade individual ou metaindividual reputado essencial para coexistência e desenvolvimento do homem em sociedade e, por isso, jurídico-penalmente protegido. E, segundo a concepção aqui acolhida, deve estar sempre em compasso com o quadro axiológico (Wertbild) vazado na Constituição e com compromisso do Estado Democrático e Social de Direito". (PRADO, 2004, p. 44). Ao discorrer sobre a conceituação do bem jurídico e a sua integração a uma realidade empírica, Claus Roxin complementa: "Também direitos fundamentais e humanos, como livre 
como determinação de conceitos e dos termos que serão empregados durante o trabalho. Portanto, para a análise do conceito de vida humana dependente, ou seja, vida anterior ao nascimento, será necessário discorrer de forma breve sobre as etapas de desenvolvimento embrionário. Isto porque, conforme já assinalado, o direito protege a vida em seus diferentes estágios, de forma incremental e gradual, tipificando condutas que atendem conta a vida humana dependente e independente e cominando sanções penais de forma variada. Portanto, é preciso entender o porquê alguns marcos são considerados decisórios e valorados de forma a determinar a implementação da tutela penal da vida humana ou a ampliação.

De forma direta e não exaustiva, é possível indicar algumas posições principais acerca do início da vida humana: com a fecundação; com a nidação; com a formação do sistema nervoso central; quando o feto passa a ter capacidade de sobreviver de forma independente do corpo da mulher ou com o desenvolvimento de um sistema moral (autoconsciência). A partir desse trabalho, será possível entender que o desenvolvimento humano inicia-se com a fecundação, mas será com a nidação que se iniciará a gestação propriamente dita, bem como o surgimento de um ser único (irrepetível), uno e indivisível ${ }^{11}$.

O processo de fecundação tem duração de aproximadamente vinte e quatro horas, iniciando-se com o contato do espermatozoide com o óvulo na tuba uterina e terminando com a mistura dos cromossomos paternos e maternos na primeira divisão celular (mitótica), formando um embrião unicelular (zigoto). Qualquer alteração na sequência dos eventos da fecundação ou em qualquer estágio pode causar a morte do zigoto $^{12}$.

desenvolvimento da personalidade, a liberdade de opinião e religiosa, também são bens jurídicos. Seu desconhecimento prejudica verdadeiramente a vida na sociedade. [...].” (ROXIN, 2009, p. 18).

11 "No caso de embriões (e fetos) em fase gestacional, com vida uterina, nítida é a titularidade de direitos fundamentais, especialmente no que concerne à proteção e conservação de suas vidas, e onde já se pode, inclusive, reconhecer como imanentes os direitos da personalidade, assim como, em alguns casos, direitos de natureza patrimonial. Na seara de proteção peal de bens fundamentais, situa-se a proibição- ainda que não absoluta- do aborto. Por outro lado, embora a tendência dominante de assegurar à vida uterina pelo menos uma proteção jurídico fundamental objetiva, segue intenso o debate sobre os limites a respeito da gravidez no caso de anencefalia (admitida pelo STF), assim como a discussão - igualmente travada no STF a respeito da legislação sobre a biotecnologia, designadamente naquilo que está em casa a determinação do início da vida e da sua necessária proteção." (SARLET, 2015, p. 226).

12 "O zigoto é geneticamente único porque metade dos cromossomos é materna e a outra metade é paterna. $\mathrm{O}$ zigoto contém uma nova combinação de cromossomos diferente da combinação das células paternas. Esse mecanismo é a base da herança biparental e da variação da espécie humana. A meiose possibilita a distribuição aleatória dos cromossomos paternos e maternos entre as células germinativas (Fig. 2-2). O crossing-over dos cromossomos, por relocação dos segmentos dos cromossomos paterno e materno "embaralha" os genes, produzindo uma recombinação do material genético. O sexo cromossômico do embrião é determinado na fecundação dependendo do tipo de espermatozoide (X ou Y) que fecunde o oócito. A fecundação por um espermatozoide que carrega o cromossomo X produz um zigoto 46, XX, que se desenvolve em um embrião feminino; já a fecundação por um espermatozoide que carrega o cromossomo Y gera um zigoto 46, XY, que se desenvolve em um embrião masculino." (MOORE; PERSAUD, 2016, p. $58)$. 
Há um progresso qualitativo, que acontece no desenvolvimento da vida humana em formação, quando o embrião se fixa no útero materno, que implica em uma distinção axiológica, pois a partir desse momento, o pré-embrião torna-se um embrião, dando início à gestação propriamente dita. Assim como o parto, do ponto de vista ontológico, a nidação confere um nova significação à pessoa humana ${ }^{13}$.

Além disso, uma grande quantidade de óvulos fecundados é abortada espontaneamente. Os estágios iniciais da implantação do blastocisto são períodos críticos de desenvolvimento que podem não ocorrer devido à produção inadequada de progesterona e estrógeno. Geralmente a mulher que teve seu período menstrual atrasado por vários dias e o fluxo menstrual aumentado, provavelmente sofreu um aborto espontâneo precoce. Embora de difícil apuração da taxa de abortos espontâneos até a nidação, já que a mulher nem chega a ter conhecimento da gravidez, sabe-se que é elevada ${ }^{14}$.

Após o período embrionário (até a oitava semana), o ser humano em desenvolvimento é chamado de feto. Durante o período fetal, ou seja, da nona semana até o nascimento, ocorre o crescimento e a diferenciação dos tecidos e órgãos formados durante o período embrionário. É a fase em que o crescimento corporal e a maturação dos órgãos se tornam notáveis, ganhando relevância especial durante o terceiro e quarto mês.

Após sucessivas divisões, a implantação do pré-embrião, que se iniciou na primeira semana de desenvolvimento, se completará com o fim da segunda semana. Será somente com a implantação do blastocisto no útero, fenômeno denominado de "nidação", que haverá produção de hCG suficiente para possibilitar o exame de gravidez idôneo. Isto porque, os testes de gravidez são baseados na quantidade desse hormônio denominado hCG e que só estará em quantidade suficiente para possibilitar um resultado positivo e confiável de gravidez com o fim da nidação, ou seja, mais ou menos, na segunda semana após a ovulação/fecundação.

13 “A nidação começa cerca de sete dias após a fecundação, quando o embrião alcança a fase de blastocisto, e termina por volta dos quatorze dias. É importante observar que, até o momento da nidação, o ser humano ainda não se encontra perfeitamente individualizado, pois não possui as características de unicidade (qualidade de ser uno e indivisível) e unidade (ser único e inconfundível): a primeira exclui a possibilidade de fomração de gêmeos univitelinos, pela divisão do zigoto em dois ou mais embriões, e se segunda se consubstancia na garantia de que o óvulo fecundado não mais poderá fundir-se com outro embrião, dado origem às chamadas "quimeras humanas." (CARVALHO, 2007, p. 33).

14 "Hertig (1975), estudando histologicamente ovos fertilizados, conclui que durante um período menstrual, a probabilidade de abortamento é $27,6 \%$. Observa-se que muitas mulheres desconhecem o estado gravídico e não imaginam seja a menstruação abundante, atrasada, na verdade, seja um abortamento subclínico." (REZENDE, 2000, p. 716). "Muitos zigotos, mórulas e blastocistos abortam espontaneamente. A implantação inicial do blastocisto representa um período crítico do desenvolvimento que pode falhar devido à produção inadequada de progesterona e de estrogênio pelo corpo lúteo (Fig. 2-7). Ocasionalmente, os médicos ouvem uma paciente declarar que seu último período menstrual atrasou por vários dias e que o último fluxo menstrual foi anormalmente abundante. Muito provavelmente essas pacientes tiveram um aborto espontâneo precoce. Acredita-se que a taxa de aborto espontâneo precoce seja de aproximadamente 45\% [...]”. (MOORE; PERSAUD, 2016, p. 66). 
Diante disso é possível afirmar que somente após a completa fixação do pré-embrião no útero materno é ocorrerá o atraso da menstruação e que será possível a confirmação da gravidez por meio de um teste fidedigno. Até o fim da nidação, ainda que por meio de controle da data da ovulação ou da data da realização da transferência do embrião para o útero, não será possível saber com certeza se há gravidez em curso.

O atraso menstrual (que deve ocorrer por volta de cinco semanas do primeiro dia da última menstruação) coincide com a terceira semana do desenvolvimento embrionário. Geralmente, a interrupção da menstruação (atraso) é o primeiro sinal de que a mulher está grávida, oportunidade em que uma gravidez normal já pode ser detectada por ultrassonografia (MOORE; PERSAUD, 2016, p. 85).

Conclui-se que o início da fase embrionária propriamente dita ocorre com a fixação do embrião no útero materno (nidação) e refere-se ao desenvolvimento humano até a oitava semana, época na qual já estão presentes as principais estruturas. Ao final desse período, o embrião possui uma aparência nitidamente humana, tendo em vista que tecidos e órgãos se formam e a forma do embrião muda (MOORE; PERSAUD, 2016, p. 105).

Vale relembrar que a fecundação ocorre na tuba uterina e não no corpo do útero (MOORE; PERSAUD, 2016, p. 58). Até a nidação, o pré-embrião é um aglomerado de células dotado de carga genética humana e que no processo de diferenciação e divisão celular dará origem tanto ao embrião humano quanto aos anexos embrionários (placenta, cordão umbilical, etc.).

$\mathrm{Na}$ fase pré-embrionária, não é possível saber quais células darão origem ao ser humano (embrião) ou aos anexos embrionários, que por sua vez também são necessários ao desenvolvimento. Ainda, não é possível saber se é o pré-embrião (aglomerado de células indiferenciadas) dará origem a apenas um embrião ou, no caso de gestação de gêmeos, a mais de um embrião. Por essas razões que convencionou-se a chamar o embrião antes da completa implantação no útero ou até o $14^{\circ}$ dia de pré-embrião, pelos motivos já expostos faltam-lhe condições intrínsecas e ambientais para serem considerados embriões humanos ${ }^{15}$.

Ainda, será entre o $14^{\mathrm{a}}$ dia e o $15^{\circ}$ dia após a fertilização, ou seja, o anúncio da fase embrionária tanto em embriões in útero, quanto em embriões extracorpóreos (in vitro), haverá o início da formação da linha primitiva, da qual se origina a coluna vertebral (SALEM, 1997, p. $82)$.

15 "Insiste-se que a importância desse evento deriva do fato de ele demarcar o último estágio no qual pode ocorrer a duplicação espontânea do embrião. Isto é, até esse momento as células que compõem o embrião (ou, caso se prefira, o pré-embrião) podem se dividir em grupos de células idênticas, dando origem a dois ou mais indivíduos idênticos." (SALEM, 1997, p. 82). 
Após o período embrionário (até a oitava semana), o ser humano em desenvolvimento é chamado de feto. Durante o período fetal, ou seja, da nona semana até o nascimento, ocorre o crescimento e a diferenciação dos tecidos e órgãos formados durante o período embrionário. É a fase em que o crescimento corporal e a maturação dos órgãos se tornam notáveis, ganhando relevância especial durante o terceiro e quarto mês.

Após essa breve explicação, é importante que fique claro ao leitor que o pré-embrião constitui uma etapa do desenvolvimento embrionário humano compreendido pelo período de formação do zigoto (óvulo fecundado pelo espermatozoide) até a nidação (fixação) no útero materno. Também é importante a compreensão de que, até esta fase embrionária, não se iniciou o processo de diferenciação celular, ou seja, o pré-embrião humano constitui um aglomerado de células indiferenciadas que poderão dar origem a um ou mais embriões (gravidez múltipla) e, ainda, aos anexos embrionários. Por isso, quando se fala em pré-embrião, não é possível definir e delimitar quais células poderão dar origem a um ser humano, isto quando a reprodução humana ocorre de forma satisfatória, ou seja, quando após a implantação haverá uma gravidez em curso. Por outro lado, o pré-embrião possui toda a carga genética humana, ou seja, possui o patrimônio genético humano, ainda que, por qualquer motivo, não venha a dar origem a um ser humano.

O NASCITURO E OS DIREITOS DA PERSONALIDADE

Os direitos da personalidade são direitos subjetivos, assegurados por norma jurídica (direito objetivo), que concedem ao titular do direito (pessoa) a faculdade de agir em defesa dos seus interesses, com o fim assegurar livre integral desenvolvimento da personalidade. Por consequência, os direitos da personalidade estão intimamente ligados aos conceitos de direitos fundamentais, dignidade humana e pessoa. Em outras palavras, vale dizer que o Constituinte brasileiro (1988), por considerar a dignidade da pessoa humana um valor supremo e o fundamento de todos os outros direitos básicos, positivou uma série de direitos (denominados direitos fundamentais), com o objetivo de criar uma redoma protetora em torno da pessoa e, portanto, para garantir o livre desenvolvimento da individualidade física e espiritual de cada ser humano (BARROSO, 2014, p. 21-22; 64-65).

A ideia de personalidade está intimamente relacionada ao conceito de pessoa, que se traduz como uma aptidão genética para ser sujeito de direitos e obrigações. Este trabalho deixará de lado o conceito de pessoas como entes morais (pessoas jurídicas) ou coletivos, para concentrar esforços em função das pessoas naturais. A proteção à pessoa humana não depende da consciência, vontade ou da própria autonomia do indivíduo. Isto porque, o recém-nascido, a 
criança, o deficiente, o portador de enfermidade grave ou, até mesmo, o ser humano em estado vegetativo, sem qualquer interação social e moral ou conhecimento da realidade, é uma pessoa e por isso dotada de personalidade. Portanto, a personalidade é um atributo inseparável do ser humano, qualidade que não depende de qualquer requisito psíquico. Sua duração é a da vida, ou seja, toda pessoa desde que viva e enquanto viva terá personalidade. Dado isso, surge o problema do início da existência, da vida e da própria personalidade do ser humano, que por vezes se confundem (PEREIRA, 2011, p.179-180).

A definição do momento da morte também é de extrema importância. A Lei 9.434/97, em seu artigo $3^{\circ}$, considera a morte encefálica como fim da vida, possibilitando a doação de órgãos singulares e vitais, tendo em vista que a doação de órgãos duplos em vida é possível ${ }^{16}$.

Portanto, os direitos da personalidade nascem e se extinguem com a pessoa. A concepção que predominou, acerca do início da personalidade civil no Código Civil brasileiro, foi a teoria natalista, nos seguintes termos: "a personalidade civil da pessoa começa do nascimento com vida; mas a lei põe a salvo, desde a concepção, os direitos do nascituro" (BRASIL, 2002). Desse modo, o conceito de pessoa civilista está adstrito à vida humana independente. Ocorre que o próprio Código Civil salvaguarda os direitos do nascituro ${ }^{17}$ (aquele que está apto a nascer) desde a concepção, possibilitando assim a sua preservação.

Apesar de existir controvérsias acerca de qual teoria adotada pelo Código Civil, o Supremo Tribunal Federal, ao julgar sobre a constitucionalidade do artigo $5^{\circ}$ da Lei Federal $n^{\circ}$ 11.105 ("Lei da Biossegurança"), corroborou o entendimento que a teoria adotada seria a natalista $^{18}$.

16 Sobre o momento da morte: “A morte encefálica consiste, portanto, na cessação definitiva das funções cerebrais do tronco do encéfalo, independente do fato de que sejam artificialmente mantidas as atividades cardiorrespiratórias. Destarte, com a superveniência da morte encefálica, desaparece a obrigação para o médico, de prosseguir com a atividade terapêutica ou de inicial um novo tratamento, e a desconexão de ventiladores artificiais e marcapassos ou a interrupção da alimentação por intubação não realiza o tipo objetivo de homicídio." (CARVALHO, 2001, p. 106-107).

17 "Razão porque o nosso Código Civil se reporta à lei para colocar a salvo, "desde a concepção, os direitos do nascituro" (do latim "nasciturus"); que são direitos de quem se encontre a caminho do nascimento. Se se prefere - considerado o fato de que o fenômeno da concepção já não é exclusivamente intracorpóreo -, direitos para cujo desfrute se faz necessário um vínculo operacional entre a fertilização do óvulo feminino e a virtualidade para avançar na trilha do nascimento. Pois essa aptidão para avançar, concretamente, na trilha do nascimento é que vai corresponder ao conceito legal de "nascituro". (BRASIL, 2008, p. 31).

18 “19. Falo "pessoas físicas ou naturais", devo explicar, para abranger tão-somente aquelas que sobrevivem ao parto feminino e por isso mesmo contempladas com o atributo a que o art. $2^{\circ}$ do Código Civil Brasileiro chama de "personalidade civil", literis: "A personalidade civil da pessoa começa do nascimento com vida; mas a lei põe a salvo, desde a concepção, os direitos do nascituro”. Donde a interpretação de que é preciso vida pós-parto para o ganho de uma personalidade perante o Direito (teoria "natalista", portanto, em oposição às teorias da "personalidade condicional" e da "concepcionista")." (BRASIL, 2008, p. 22). Comentando a decisão, Ingo Wolfgang Sarlet: "De qualquer modo, da acirrada controvérsia registrada entre as posições dos julgadores, vislumbra-se que, de acordo com o Ministro Carlos Britto, relator do Acórdão, a titularidade em si de direitos fundamentais (no caso, estava em causa o direito à vida e dignidade da 
Sendo assim, várias correntes doutrinárias tentam explicar a natureza jurídica do nascituro, as mais importantes são: teoria natalista, teoria da personalidade condicional, teoria concepcionista e teoria genético desenvolvimentista. Para a doutrina natalista a personalidade só terá início com nascimento com vida, enquanto para a teoria da personalidade jurídica condicional, a personalidade do embrião seria potencial e condicionada a um evento futuro: nascimento com vida ${ }^{19}$.

Para distinguir as outras duas teorias, é importante salientar que a ciência, até os avanços no campo da engenharia genética, distinguia apenas dois conceitos: embrião e feto, sendo que o primeiro compreendia o período entre a fecundação (formação do zigoto) e a oitava semana, enquanto a fase fetal era demarcada a partir da oitava semana de gestação. Com a possibilidade de criopreservação de óvulos fecundados em laboratório, por tempo indeterminado, foi criada uma nova terminologia: embrião pré-implantatório ou pré-embrião. Portanto, de acordo com a teoria concepcionista o desenvolvimento embrionário seria dividido em duas etapas (embrionário e fetal), enquanto, para teoria genético-desenvolvimentista seriam três fases da vida humana dependente: pré-embrionária, embrionária e fetal. Conforme já ressaltado, a fase pré-embrionária compreenderia o período da fecundação até o décimo quarto dia, sendo que a concessão de tutela deve ser diferente do embrião já ficado no útero materno (CARVALHO, 2007, p. 34-35).

Contudo, existem autores que fazem essa distinção valorativa entre o embrião antes e após a nidação, mas que ainda assim se consideram adeptos a teria concepcionista ${ }^{20}$. Isto porque, definem a concepção e início da gravidez a partir do momento da fixação do ovo no útero materno $^{21}$. Nesse sentido, quando a concepção é considerada a partir da nidificação e não da fecundação, não há uma diferença substancial, mas apenas terminológica, entre as correntes concepcionistas e genético desenvolvimentista.

pessoa)- o que, ainda que não expressamente, acabou tendo apoio da maioria dos Ministros- está reservada à pessoa, porquanto, ao indivíduo nascido com vida." (SARLET, 2015, p. 228).

19 "Poder-se-ia até mesmo afirmar que na vida intrauterina tem o nascituro e na vida extrauterina tem o embrião, concebido in vitro, personalidade jurídica formal, no que atina aos direitos da personalidade, visto ter carga genética diferenciada desde a concepção, seja ela in vivo ou in vitro (PL n. 699/2011, art. $2^{\circ}$, Recomendação n. 1.046/89, n.7, do Conselho da Europa; Pacto de São José da Costa Rica, art. 4º I; Resolução do CFM n. 2013/2013), Seções IV, n. 3, V, VI), passando a ter responsabilidade jurídica material, alcançando os direitos patrimoniais (RT, 593:258) e obrigacionais, que se encontravam em estado potencial, somente com nascimento com vida (CC, art. $\left.1800, \S 3^{\circ}\right)$. Se nascer com vida adquire personalidade jurídica material, mas se tal não ocorrer nenhum direito patrimonial terá. (DINIZ, 2014, p. 226).

20 "Ao tratarmos do início da vida, invocamos, como argumento filosófico, a doutrina aristotélica-tomista, segundo a qual, desde a concepção o homem traz em si o germe de ser racional. Do ponto de vista biológico, não há dúvida que a vida se inicia com a fecundação do óvulo pelo espermatozoide, resultando um ovo ou um zigoto. Assim o demonstram os argumentos colhidos na biologia. A vida viável começa, porém, com a nidação, quando se inicia a gravidez.” (ALMEIDA, 1988, p. 183). 
O Direito Civil parte de uma concepção de pessoa e de personalidade predominantemente patrimonialista, ao menos em sua origem, principalmente, quando se trata da questão dos direitos sucessórios do nascituro. Portanto, essa definição civilista não é suficiente para valorar a proteção da vida humana, bem como de outros direitos essenciais ou, como já tratado, os direitos que compreendem o primeiro centro ou dever de tutela, tendo em vista que se refere à própria realidade subsistente do ser humano.

O próprio Código Civil, mesmo não reconhecendo o status de pessoa ao nascituro, protege os direitos essenciais à própria existência do feto ou embrião, como por exemplo, o direito à vida, à integridade física e à saúde. Essa postura permite concluir que a adoção pelo legislador da teoria natalista reflete uma preocupação com os efeitos patrimoniais (sucessórios) do que propriamente com os direitos da personalidade de caráter existenciais. Apesar da necessidade de unidade e integração do ordenamento jurídico, a transposição da teria natalista/civilista para todos os ramos do direito pode ser considerada no mínimo precipitada. Ainda que a maior parte da doutrina não reconheça a condição de pessoa, é possível dizer com clareza que o Direito Penal, o Direito Internacional e o Direito Constitucional (bloco de constitucionalidade) tutelam a vida humana pré-natal de forma independente, ou seja, por si só.

Além disso, os avanços das novas técnicas de manipulação genética, diagnósticos prénatais, criopreservação de embriões, dentre outros, levam a questionamentos éticos, morais e jurídicos, dentre eles a necessidade de ressignificação do conceito de ser humano enquanto pessoa. Isto porque, além do maior conhecimento acerca das fases do desenvolvimento humano (em especial o embrionário), essas novas técnicas possibilitaram novas formas de perigo e de risco de lesão ao ser humano, até então desconhecidas. Demais disso, o Código Civil, ao adotar a teoria natalista e resguardar os direitos do nascituro, omitiu-se com relação ao embrião extracorpóreo.

\section{5}

\section{DA TIPICIDADE DO DELITO DE ABORTO}

O bem jurídico tutelado no crime de aborto é a vida humana pré-natal, portanto as condutas criminosas devem recair sobre o embrião ou feto humanos vivos, desde que dentro do útero da mulher (PRADO; CARVALHO, 2017). A maioria da comunidade científica afirma que a vida começa com a fecundação, mas a proteção jurídica torna-se necessária e possível somente a partir da nidação, ou seja, com início propriamente dito da gestação.

Em que pese os delitos em questão estarem situados no título "dos crimes contra a pessoa” e capítulo "dos crimes contra a vida”, conforme já assinalado, a doutrina (em geral) não 
considera o embrião e o feto humano uma pessoa ${ }^{22}$, apesar de concordarem que não se trata de uma parte do corpo da mãe $e^{23}$. As condutas são tipificadas nos artigos 124 a 126 do Código Penal e possuem como núcleo do tipo objetivo o verbo "provocar", que consistem em causar, dar origem ou promover o aborto. Contudo, nenhum dos tipos penais definem o que se entende por "aborto", logo, se trata de um elemento normativo extrajurídico, cuja definição exige um juízo de valor dado pelas ciências médicas e biológicas (CARVALHO, 2017). Nesse sentido, Cézar Roberto Bittencourt exemplifica: "Nosso atual Código Penal também não o define, limitando-se a adotar a fórmula neutra e indeterminada "provocar o aborto", algo semelhante a, somente para exemplificar, "provocar homicídio", em vez de "matar alguém" (BITENCOURT, 2015, p. 169).

O aborto criminoso pode ser conceituado como a utilização dolosa de manobras que acarretem a interrupção ilícita da gravidez normal ${ }^{24}$, pouco importando o estágio de desenvolvimento humano, desde que ocasione a morte do embrião ou feto, dentro ou fora do útero, seguida ou não da sua expulsão. Diante disso, haverá crime de aborto, mesmo que não ocorra a expulsão do produto da concepção, como por exemplo no caso de absorção pelo organismo materno. Ainda, configurará o tipo penal do aborto quando há morte do feto, mesmo que ocorra fora do corpo materno- não sobrevive a sua expulsão prematura- seja resultado dos atos praticados para a interrupção da gravide $z^{25}$. Isso significa dizer que, o crime de aborto estará consumado mesmo que o feto nasça vivo, mas venha a falecer em seguida, em razão dos meios abortivos empregados ${ }^{26}$. Contudo, se houver o nascimento com vida e o resultado morte decorra de outras causas independentes, pode-se dizer que o crime de aborto será tentado (PRADO; CARVALHO, 2017).

22 “O objeto da tutela jurídica é a vida da pessoa em formação, o que justifica a classificação do fato, embora a rigor não se trate de crime contra a pessoa". (FRAGOSO, 1995, p. 80).

23 Ver em: "O bem jurídico protegido é a vida do ser humano em formação, embora, rigorosamente falando, não se trate de crime contra a pessoa. O produto da concepção- feto ou embrião- não é pessoa, embora tampouco seja mera esperança de vida ou simples parte do corpo materno, como alguns doutrinadores sustentam, pois tem vida própria e recebe tratamento autônomo na ordem jurídica. Quando o aborto é provocado por terceiro, o tipo penal protege também a incolumidade da gestante". (BITENCOURT, 2015, p. 168).

24 "A interrupção da gravidez extrauterina ou da gravidez molar não configura o delito de aborto." (CARVALHO, 2017, n. p.).

25 "Por lo general, se coincide em estimar que desde uma perspectiva penal do aborto consiste em dar uma muerte al embrión i feto humanos, bien en el interior del caustro materno, bien provocando su expulsión prematura do mismo. Em este último caso hay quien exige la falta de viabilidade y madurez del feto expulsado". (CASABONA, 1994, p. 284-285).

26 "Admitida a intenção de provocar o aborto, ou, seja, de suprimir o feto, não tem importância o momento em que este vem a morrer: se quando ainda no útero materno, ou já expulso, uma vez que a morte tenha ocorrido em consequência da própria imaturidade do feto ou dos meios abortivos empregados". (HUNGRIA, 1942, p. 252). 
Portanto, para que configure o crime de aborto são necessários os seguintes requisitos: prova da existência da gravidez ${ }^{27}$, emprego de técnicas abortivas (diretas ou indiretas), conduta dolosa e morte do embrião ou feto causada pelo uso das manobras abortivas (DINIZ, 2014, p. 36-37).

Conclui-se que necessariamente o crime de aborto pressupõe gravidez em curso, embrião ou feto vivo e que a sua morte seja resultado direto dos métodos abortivos ${ }^{28} \mathrm{e}$, em razão disso, o tipo tem como termo inicial, ou seja, limite temporal mínimo necessário para sua tipicidade "a nidação" (PRADO, 2007, p. 113). Antes dessa fase, não há que se falar em crime, logo, a fixação no útero materno é o fato que determina o início da proteção penal da vida intrauterina ${ }^{29}$. É nesse momento, que a vida humana ganha magnitude suficiente para orientar a atividade jurídica, pois a partir de então o ser humano alcança a condição ambiental necessária para o desenvolvimento embrionário, tornando-se efetivamente um nascituro (aquele que tem aptidão para nascer) (MALANDA, 2006, p. 127).

É devido a essa delimitação do âmbito de proteção jurídico-penal da vida humana dependente, que os métodos contraceptivos de urgência ou pós-coital ${ }^{30}$ não se enquadram nesses tipos penais. Os métodos em questão são: contracepção hormonal de urgência (método Yuzpe e levonorgestrel) e dispositivo intrauterino de cobre, que inibem ou retardam a ovulação e quando essa já ocorreu, alteram a parede do endométrio impedindo a fixação do ovo no útero materno. A pílula de urgência pode ser administrada com eficácia até 72 horas pós-coito, após esse lapso temporal poderá ser utilizado o DIU até o $5^{\circ}$ dia, em nenhum caso alcança o termo inicial do conceito doutrinário de aborto (HALBE; CUNHA; RAMOS, 1998).

27 “O exame de corpo delito é indispensável (art. 158, CPP) e se realiza com o exame da mulher e, se possível, do produto da concepção. A ausência do exame de corpo de delito constitui nulidade processual (art. 564, II, b, CPP). [...] Não pode ele ser suprido pela confissão da gestante [...].” (FRAGOSO, 1995, p. 82).

28 "De fato, a mera interrupção da gestação, por si só, não implica aborto, dado que o feto pode ser expulso do ventre materno e sobreviver ou, embora com vida, ser morto por outra conduta punível (infanticídio ou homicídio). Atualmente, com as modernas técnicas de reprodução assistida, não é possível sustentar tal relação de causa e efeito (interrupção da gravidez/destruição do nascituro), pois pode o embrião ser transferido para outra mulher. Além disso, é bem possível a destruição de um dos embriões ou fetos - na hipótese de gravidez múltipla - sem a interrupção do processo de gestação". (PRADO; CARVALHO, 2017, n. p.).

29 "Destarte, o aborto tem como limite mínimo necessário para sua existência a nidação, que ocorre cerca de quatorze dias após a concepção. O termo final é o início do parto, que, conforme examinado, é marcado pelas contrações da dilatação (parto normal) ou com o início dos procedimentos cirúrgicos (v.g., cesariana)." (PRADO; CARVALHO, 2017, n. p.).

30 "Tres ejemplos sobre cada una de estas situaciones bastarán para poner de relieve que tiene para el Derecho delimitar cada una de estas fases o estadios de la vida: a) supongamos que una mujer, después de haber mantenido una relación sexual, se aplica una píldora de las llamadas "del día después” y gracias a su acción el óvulo fecundado no se implanta; o si provoca una " regulación menstrual”, dentro de las dos primeras semanas después de la desaparición del período menstrual; pues bien ¿ serán calificables estas conductas de aborto? ¿serán, si la respuesta es afirmativa, punibles, si la ley penal no indica ninguna especificación al respecto (a partir de cuándo se protege el ser concebido)?” (CASABONA, 1994, p. 130-140). 
Somente a partir desse termo inicial (nidação), a proteção penal torna-se possível, em razão da aparição do bem jurídico a ser protegido e da própria configuração do tipo penal objetivo e subjetivo, ou seja, a existência propriamente dita de uma gestação e de uma vida irrepetível (tipo objetivo), bem como da possibilidade de conhecimento da gravidez (dolo). Manobras abortivas realizadas em mulher não grávida, em razão da absoluta impropriedade do objeto, configurará crime impossível ${ }^{31}$.

É nesse mesmo sentido, que a condutas praticadas contra embriões fecundados in vitro ou extracorpóreo não se enquadram no tipo de aborto. Conforme será visto no capítulo seguinte, a utilização de embrião humano (in vitro) em desacordo com o disposto no artigo $5^{\circ}$ da Lei de Biossegurança (Lei 11.105/05) pode configurar algum dos delitos tipificados nessa lei especial.

Além disso, é importante ressaltar que não está previsto no ordenamento penal brasileiro o delito de aborto culposo, portanto o aborto causado por inobservância do cuidado objetivamente devido não é punível. Dito de outro modo, o tipo subjetivo do delito de aborto é constituído pelo dolo, ou seja, pela vontade consciente de provocar a morte do feto ${ }^{32}$, portanto há a necessidade que todos os elementos do tipo penal sejam conhecidos pelo sujeito, em especial a existência da gestação. Admite-se, ainda, a modalidade do dolo eventual, quando o agente não quer a morte do embrião ou feto como resultado específico da sua ação, mas aceita como possível ou provável o resultado e assume o risco ${ }^{33}$.

Quando se trata da criminalização ou descriminalização do aborto, é possível encontrar diversas posturas que oscilam entre as mais radicais no sentido de proibir ou admitir o aborto de forma absoluta, em quaisquer situações e sem exceções.

Após essa primeira parte, é imprescindível afirmar que, no ordenamento jurídico brasileiro, a vida humana em formação não é tutelada de forma absoluta, ou seja, o legislador infraconstitucional, além de valorar de maneira incremental e gradual a vida humana, adotou soluções para descriminalização parcial do aborto voluntário. Isto porque, não é possível afirmar,

31 "Há crime impossível, por exemplo, nas manobras abortivas em mulher que não está gravida ou no caso de o feto há estar morto antes da prática dos atos abortivos, por absoluta improbidade do objeto; ou, ainda, por inadequação absoluta do meio, quando for inteiramente inidôneo para produzir o resultado, como rezas feitiçarias ou a administração de substâncias absolutamente inócuas”. (BITENCOURT, 2015, p. 175).

32 “65- O dolo. O aborto só é punível a título de dolo, que é, na espécie, a vontade consciente e livre de interromper a gravidez ou eliminar o produto da concepção, ou, pelo menos, a anuência do prevista advento previsto de tais resultados. Não constitui crime o aborto culposo ou preterintencional. É de notar, porém, que o aborto preterintencional, do mesmo modo que a simples aceleração do parto não compreendida no dolo do agente, é previsto como condição maior de punibilidade no crime de lesões corporais (artigo 129, $\S 2 .^{\circ}$, n. $^{\circ} \mathrm{V}$, e $§ 1 .^{\circ}$, n. $^{\circ}$ IV);”. (HUNGRIA, 1942, p. 253).

33 "O crime de aborto somente é punível a título de dolo, que consiste na vontade livre e consciente de interromper a gravidez, matando o produto da concepção (dolo direto), ou na aceitação do risco de provocar esse resultado (dolo eventual). O dolo eventual pode resultar de dúvida quanto à gravides". (FRAGOSO, 1995 , p. 82). 
como já dito anteriormente, que há uma absoluta preeminência de algum direito sobre todos os demais, nem mesmo com relação ao direito à vida, tendo em vista que em certos casos é possível privar licitamente outra pessoa desse direito, sem que isso seja considerado ilícito, como por exemplo, em situação de legítima defesa ou estado de necessidade no delito de homicídio ${ }^{34}$. Com relação à política-criminal ${ }^{35}$ acerca da tipicidade e ilicitude do crime do aborto, o legislador brasileiro adotou o sistema de indicações, em que a vida intrauterina é um bem jurídico digno da proteção penal, o que justifica a criminalização do aborto voluntário, inclusive do autoaborto e do aborto consentido. Contudo, diante de certas circunstâncias, ou seja, quando existente um conflito entre a vida do concebido com determinados interesses da genitora, aquele deve ceder em razão destes. Em síntese, trata-se do esquema regra-exceção, em que a regra é a punição do aborto voluntário, enquanto as exceções são indicadas pelo próprio legislador, no exercício do poder soberano, em que a vida do embrião e feto deve ceder em face de interesses maternos mais valiosos.

Em razão do sistema adotado, a vida humana em formação não se encontra desprotegida de modo absoluto em nenhuma fase do seu desenvolvimento gestacional e, mesmo assim, é possível conciliar algumas necessidades relevantes da genitora (vida, saúde, liberdade e intimidade). Essa solução adotada pelo legislador é uma "solução de compromisso", pois:

[...] somente os casos (indicações, exceções estabelecidas por lei, e com os requisitos que exige, o aborto pode ser realizado, o que contribui para uma maior segurança jurídica (sabe-se exatamente quando é permitido e quando não) e evita subjetivismo ou dúvidas na determinação do que é o interesse preponderante na situação concreta" (CASABONA, 2003, p. 295, tradução nossa). ${ }^{36}$

As seguintes indicações geralmente são aceitas nas legislações de diversos países: a terapêutica (em casos de grave perigo para a vida ou a saúde da mãe); a sentimental, ética ou criminológica (a gravidez resultante de delito de natureza sexual ou de técnica de reprodução assistida não consentida pela mulher); a eugenésica (riscos comprovados

34 Nesse sentido: ver Casabona (2003, p. 293).

35 "Do incessante processo de mudança social, dos resultados que apresentem novas ou antigas propostas do direito penal, das revelações empíricas propiciadas pelo desempenho das instituições que integram o sistema penal, dos avanços e descobertas da criminologia, surgem princípios e recomendações para a reforma ou transformação da legislação criminal e dos órgãos encarregados de sua aplicação. A esse conjunto de princípios e recomendações denomina-se política criminal”. (BATISTA, 2007, p. 34).

36 “"...] sólo en los supuestos (indicaciones, excepciones) preestablecidos por la ley, y com lós requisitos que ella exija, podrá realizarse el aborto, lo que contribuye a una mayor seguridad jurídica (se sabe exactamente cuándo está permitidoy cuándo no) y evita subjetivismos ou dudas em la determinación de cuál es el interés preponderante em la situación concreta [...].” 
de grave anomalia do embrião ou feto); e a econômico-social (quando razões financeiras, prole numerosa e miséria justificam a conduta).

Dentre as situações indicadas acima e permitidas em algumas legislações, o legislador infraconstitucional brasileiro adotou somente o aborto terapêutico e sentimental (com restrições), constantes no artigo 128 do Código Penal. Portanto, o aborto praticado por médico não será punido em duas situações: se não houver outro meio de salvar a vida da gestante (indicação de natureza terapêutica) ou se a gravidez resultar de estupro e o aborto for precedido do consentimento da gestante ou, quando incapaz, de seu representante legal (indicação de natureza sentimental).

Com relação ao aborto terapêutico, a possibilidade da realização do aborto está justificada assim como no estado de necessidade, enquanto no aborto sentimental ou humanitário, o fundamento seria a inexigibilidade de conduta diversa (causa de exclusão da culpabilidade). Para a realização do aborto humanitário pelo médico, não serão necessárias a preexistência de sentença condenatória do delito sexual (estupro) ou, ainda, de autorização judicial, bastando que a intervenção médica seja justificada por elementos de convicção substanciais (v.g., boletim de ocorrência, declarações etc.). Vale ressaltar que não há possibilidade de analogia com o objetivo de estender a possibilidade de realização do aborto quando de outros crimes de natureza sexual.

A indicação eugenésica ou eugênica ${ }^{37}$ não está prevista na legislação penal brasileira. Contudo, ao discorrer acerca do aborto eugênico, é imprescindível mencionar a hipótese de anencefalia, que pode ser definida como ausência parcial congênita das estruturas cerebrais. O feto anencefálico não desenvolve as funções superiores do sistema nervoso central e, portanto, dificilmente alcança os estágios mais avançados da vida intrauterina.

O exame mais utilizado para detectar anomalias e más-formações fetais é a ecografia ${ }^{38} \mathrm{e}$, de acordo com a doutrina, o índice de falibilidade do exame é praticamente nulo, ou seja, o resultado é capaz de gerar uma certeza médica confortável (BARROSO, 2005, p. 95).

A discussão ganhou relevância no Brasil, quando a Confederação Nacional dos Trabalhadores na Saúde protocolou junto ao Supremo Tribunal Federal a ADPF (Arguição de

37 "Dentro da finalidade visada pela indicação eugenésica, cabe diferenciar a priori entre quatro tipos ou modalidades na prática do aborto, independentemente de qual seja a fundamentação adotada. Em primeiro lugar, e esta seria a forma mais primitiva de previsão, seria o aborto praticado em mulher grávida deficiente. Em segundo lugar, o aborto praticado em razão da idade avançada da mulher grávida. Em terceiro, o aborto praticado, sem diagnóstico pré-natal, em virtude das características dos pais, constituindo o aborto eugenésico "preventivo" uma modalidade dessa hipótese. Por fim, o aborto praticado quando do diagnóstico pré-natal se deduz ou se presume a existência de determinadas doenças - graves ou incuráveis - no ser em gestação." (PRADO; CARVALHO, 2017, n. p.).

38 Cf. Art. $2^{\circ}$. (BRASIL, 2012, p. 308). 
Descumprimento de Preceito Fundamental) $n^{0} 54$, com o objetivo que a corte reconhecesse o direito de antecipação terapêutica do parto nas hipóteses de gestação de feto anencefálicos.

Em abril de 2012, o aborto eugênico na hipótese de gestação de feto anencefálico passou a ser autorizada expressamente, quando os ministros do Supremo Tribunal Federal decidiram, por 8 (oito) votos a favor e 2 (dois) contra, que a antecipação terapêutica do parto no caso de anencefalia não pode ser considerada uma conduta típica ${ }^{39}$, nos termos da Constituição, tendo em vista a inexistência da vida humana ${ }^{40}$, e ainda em razão dos riscos que da gestação para a vida e saúde da gestante ${ }^{41}$.

\section{6 \\ ABORTO ATÉ OS TRÊS MESES de GESTAÇÃO: BREVES CONSIDERAÇÕES ACERCA DA DECISÃO DA PRIMEIRA TURMA DO SUPREMO TRIBUNAL FEDERAL}

No ano de 2016, a Primeira Turma do Supremo Tribunal Federal julgou o Habeas Corpus $\mathrm{n}^{\mathrm{o}} 124.306 / 2016$, oportunidade em que, sob escusa de uma interpretação conforme a Constituição, considerou atípico o aborto praticado até o terceiro mês de gestação. Nessa decisão, o Supremo Tribunal Federal afastou a prisão preventiva dos denunciados pelo Ministério Público do Rio de Janeiro pela suposta prática do crime de abordo- com consentimento da gestante e formação de quadrilha (artigos 126 e 288 do Código Penal).

A decisão gerou grande euforia entre os juristas e a comunidade no que se refere ao tipo penal aborto. Isto porque, de acordo com o voto do ministro Luís Roberto Barroso ${ }^{42}$, que alcançou a maioria da primeira turma, a interrupção voluntária da gestação até o primeiro trimestre de gestação não configuraria delito de aborto (BRASIL, 2017).

39 “.... Mostra-se inconstitucional interpretação de a interrupção da gravidez de feto anencéfalo ser conduta tipificada nos artigos 124, 126 e 128, incisos I e II, do Código Penal.” (ADPF 54, Relator(a): Min. MARCO AURÉLIO, Tribunal Pleno, julgado em 12/04/2012, ACÓRDÃO ELETRÔNICO DJe-080 DIVULG 2904-2013 PUBLIC 30-04-2013 RTJ VOL-00226-01 PP-00011).

40 Não foi por outra razão que o Conselho Federal de Medicina, mediante a Resolução $\mathrm{n}^{\circ}$ 1.752/2004, consignou serem os anencéfalos natimortos cerebrais. $O$ anencéfalo jamais se tornará uma pessoa. Em síntese, não se cuida de vida em potencial, mas de morte segura. [...] O anencéfalo é um natimorto. Não há vida em potencial." (BRASIL, 2012b, p. 15-17).

41 “Apenas, se preferir, a gestante poderá aguardar o curso natural do ciclo biológico, mas, em contrapartida, não será "condenada" a abrigar dentro de si um tormento que aniquila, brutaliza, desumaniza e destrói emocional e psicologicamente, visto que, ao contrário de outras gestantes que se preparam para dar à luz a vida, regozijando-se com a beleza da repetição milenar da natureza, afoga-se na tristeza, no desgosto e na desilusão de ser condenada a- além da perda irreparável- continuar abrigando em seu ventre um ser inanimado, disforme e sem vida, aguardando o dia para, ao invés de brindar o nascimento do filho como todas as mães sonham, convidar os vizinhos para ajudá-la enterrar um natimorto, que nunca teve a chance alguma de nascer com vida.”. (BITENCOURT, 2015, p. 180).

42 Nesse mesmo sentido: BARROSO, Luís Roberto. A dignidade da pessoa humana no direito constitucional contemporâneo. A construção de um conceito jurídico à luz da jurisprudência Mundial. 3. ed. Belo Horizonte: Fórum, 2014. 
De acordo com o voto de vista, o ministro reconheceu a relevância do bem jurídico (tutela da vida humana intrauterina), mas consignou que a criminalização do aborto antes do primeiro trimestre violaria os direitos: sexuais; reprodutivos; à autonomia ${ }^{43}$; à integridade física; à psíquica e à igualdade (equiparação plena de gênero).

Ainda, utilizou de argumento social, no sentido de que as mulheres pobres são vitimadas, tendo em vista que não possuem acesso às clínicas privadas e, em razão disso, ficam vulneráveis e suscetíveis à mutilações, lesões graves e óbitos. Demais disso, conclui que a criminalização do aborto não é um meio eficaz de evitar sua disseminação e melhor forma de proteção à vida humana ${ }^{44}$.

A decisão, de cunho extremamente ativista, violou o princípio da separação dos poderes, ao ultrapassar os limites do Poder Judiciário, invadindo a esfera de poder do legislativo, sob a escusa de que o tipo penal do aborto deveria ser interpretado conforme a constituição.

Não bastasse isso, a decisão é claramente inconvencional ${ }^{45}$, tendo em vista que o Brasil é signatário do Pacto de San José da Costa Rica, no qual se obrigou a proteger a vida por lei desde a concepção ${ }^{46}$. Além disso, já existe decisão da Corte Interamericana (CIDH, 2012), em que o artigo 4.1 do Pacto já foi interpretado, no sentido de que o termo "concepção" (ZENNI; AIRES; RIBEIRO, 2018) compreende o momento em que o embrião é implantado no útero da mulher. Diante disso, é possível dizer que há uma obrigação dos Estados-Partes em proteger a vida humana dependente a partir da nidação, exceto em casos excepcionais.

Convém salientar que no voto do ministro Luís Roberto Barroso, assim como no voto concorrente da ministra Rosa Weber, invocou-se a legislação de diversos países em que a interrupção da gestação durante o primeiro trimestre de gravidez não é criminalizada, como por exemplo “Estados Unidos, Alemanha, Reino Unido, Canadá, França, Itália, Espanha, Portugal, Holanda e Austrália” (BRASIL, 2017). Contudo, verifica-se que nenhum dos países mencionados

43 “Os argumentos, que têm sido trazidos à discussão, de que o aborto não é atentado ao direito à vida, mas o exercício de um direito ao corpo que a mulher possui, não prevalece, visto que se a própria natureza feminina faz-lhe hospedeira do direito à vida de outrem, no momento em que a hospedagem se dá, já não é mais titular solitária do seu corpo, que pertence também a seu fillho. E o egoísmo que leva a assassiná-lo, para fazer dele uso exclusivo de seus apetites, caprichos, conforto ou qualquer outro motivo, representa tirar o direito de outrem que também é titular do corpo materno. Desde a concepção, o corpo feminino pertence a duas vidas e é dirigido por dois seres, a mãe e o filho, e a mãe não pode praticar homicídio para retirar ao filho um direito que possui ao corpo materno" (MARTINS, 2009, p. 10).

44 É possível que o Estado evite a ocorrência de abortos por meios mais eficazes e menos lesivos do que a criminalização, tais como educação sexual, distribuição de contraceptivos e amparo à mulher que deseja ter o filho, mas se encontra em condições adversas; (iii) a medida é desproporcional em sentido estrito, por gerar custos sociais (problemas de saúde pública e mortes) superiores aos seus benefícios. (BRASIL, 2017, n. p.).

45 Ver sobre: MAZZUOLI, Valério de Oliveira. O controle jurisdicional da convencionalidade das leis. São Paulo: Revista dos Tribunais, 2016.

46 Artigo 4.1. (CIDH. 1969). 
ratificaram a Convenção Americana de Direitos Humanos e, portanto, não se obrigaram a proteger a vida humana (em regra) desde a concepção.

Inicialmente, tal argumento não merece prosperar, porque a liberdade sexual, a reprodutiva, a autonomia, a igualdade e todos os outros direitos mencionados não podem prevalecer ante o direito à vida em qualquer situação no ordenamento jurídico brasileiro. Isto porque há um compromisso estatal de proteção da vida desde a concepção que só poderá ser relativizado diante de outros bens jurídicos de igual modo relevantes, como por exemplo a vida e a saúde (aborto necessário). Essas situações de ponderação da vida humana dependente já foram valoradas pelo próprio legislador ao adotar o sistema de indicações (artigo 128, Código Penal), elegendo, dentre todos os bens jurídicos, em quais as situações a proteção da vida pré-natal poderá ser ponderada.

Outrossim, é importante relembrar que a restrição à liberdade e à autonomia da gestante é temporária, tendo em vista que o Estado proíbe atos atentatórios contra à vida do nascituro e, portanto, à gestação, mas não obriga a grávida exercer a maternidade após o parto.

Ainda, a comparação, realizada no acórdão do Habeas Corpus 124.306/2016 com o panorama legislativo e jurisdicional de diversos países em que a interrupção da gestação durante o primeiro trimestre de gravidez não é criminalizada, deve ser analisada com parcimônia, porque todos os Estados mencionados na decisão não assumiram o compromisso internacional de proteção da vida humana intrauterina.

Além disso, o legislador brasileiro optou por proteger a vida humana (desde o início da gestação) e fez de forma gradual, incremental e não absoluta, ou seja, relativizou essa proteção em algumas situações, adotando o sistema de indicações. Desse modo, a opção pelo sistema de prazos ou pelo sistema de indicações é uma questão de política criminal, que deve obedecer os princípios da fragmentariedade e da intervenção mínima, orientando a atividade do poder legislativo, para uma maior segurança jurídica.

O legislador ao fazer essa opção ponderou previamente os valores predominantes na sociedade, e, portanto, não cabe ao juiz ${ }^{47}$, no exercício do seu poder jurisdicional, por meio de um ativismo judicial descabido e que claramente viola o princípio mais básico do direito penal (legalidade) e a separação dos poderes, decidir sobre política criminal e optar por um sistema diferente do escolhido pelo legislador. A forma de tutela do bem jurídico, a escolha do tipo penal

47 "Por isso se diz, frequentemente, que a antijuridicidade é um "juízo de desvalor” da conduta típica. É preciso ter em conta, todavia, o caráter metafórico dessa expressão. O sujeito desse juízo de desvalor não é um indivíduo (nem sequer o juiz), mas o ordenamento jurídico, como tal. O juiz poderia, em poucas palavras repetir o juízo de desvalor da antijuridicidade do ordenamento jurídico.” (WEZEL, 2009, p. 56). 
e das excludentes de antijuridicidade ${ }^{48}$, ou seja, os limites da intervenção penal, principalmente em se tratando de vida humana, são situações previamente valoradas pelo legislador, no exercício do poder soberano, exercido de forma democrática.

\section{CONSIDERAÇÕES FINAIS}

A vida como direito fundamental é uma realidade complexa e pode ser entendida a partir de várias perspectivas. Diversos outros direitos básicos circundam o direito à vida e condicionam o nível de qualidade em sua perspectiva social (assistência médica, assistência social, lazer, educação, saneamento, dentre outros direitos fundamentais). Outrossim, é evidente a importância desse direito, pois ele é o pressuposto e suporte para a existência de todos os outros direitos e condição necessária para permitir o desenvolvimento da personalidade. Por suposto, que a sua privação é irreversível e também destitui automaticamente do exercício de todos os outros direitos.

Com objetivo de estabelecer o limite temporal da tutela penal no ordenamento jurídico brasileiro, ou seja, quando a destruição do embrião ou do feto passa a ser tipificado como delito de aborto, a vida humana dependente foi analisada a partir de uma perspectiva físico-biológica e sua proteção a partir dos princípios da dogmática penal.

Sem dúvida, a vida é um bem jurídico digno de tutela penal e o legislador infraconstitucional intensifica ou ameniza a proteção jurídica nas diferentes fases do curso vital, surgindo diversos tipos penais que atentam contra ela. Nesse sentido, o direito à vida impõe para o Estado, mais do que qualquer outro direito, a obrigação de proteção, em especial com relação aos insuficientes.

Dito de outro modo, o Estado brasileiro tem o dever de tutelar a vida humana dependente e o faz por meio do delito de aborto. Por fim, a partir desse trabalho, será possível concluir que o concebido é titular do direito à vida e à integridade física, não como integrante do corpo da genitora, mas de forma independente e autônoma, tendo em vista que são dois sistemas biológicos e seres humanos distintos e, portanto, dotados de dignidade. Portanto, a partir da concepção, o corpo da mãe é o hospedeiro de uma nova vida e o exercício do direito ao seu próprio corpo só pode ser exercido nos limites da tutela da sua vida e da vida do seu filho.

48 “Contudo, toda realização do tipo de uma norma proibitiva é contrária à norma, mas não é sempre antijurídica; pois o ordenamento jurídico não se compõe apenas de normas, mas também de preceitos permissivos ("autorizações") [...]. Nesse caso a realização de um tipo em uma norma proibitiva é jurídica. Antijuridicidade é, pois, a contradição da realização de um tipo com ordenamento jurídico em seu conjunto (não apenas com a norma isolada).” (WEZEL, 2009, p. 55). 
O aborto criminoso é conceituado como a interrupção dolosa e ilícita de uma gravidez normal (não patológica), pouco importando o estágio de desenvolvimento humano, desde que ocasione a morte do embrião ou feto. Diante disso, haverá crime de aborto com a morte de embrião ou do feto entre período compreendido pela nidação até o início do parto. Isso porque, a fixação do embrião no útero materno é um marco valorativo que determina o aparecimento do bem jurídico penal, ou seja, de um ser humano dotado de unicidade (irrepetível) e unidade, inclusive já iniciada a formação da linha primitiva, da qual se origina a coluna vertebral.

Até a decisão da Primeira Turma do Supremo Tribunal Federal, o posicionamento acerca da tipicidade do delito de aborto somente a partir do primeiro trimestre de gestação não possuía eco na doutrina. Isso porque, alguns autores até indicavam a fecundação como início da proteção penal (em oposição à nidação), que pelos motivos já expostos, não se faz necessária e possível, mas não havia expressividade o posicionamento de que o aborto criminoso somente poderia ser considerado após o terceiro mês.

Interessante ressaltar, como já comentado, que o período embrionário se inicia com a nidação e vai até a oitava semana, ao final desse período, o embrião já possui forma nitidamente humana. Durante o período fetal (da nova semana até o nascimento), ocorre o crescimento e desenvolvimentos dos órgãos que já iniciaram sua formação durante o período embrionário. Isso significa que a descriminalização do aborto até o terceiro mês permitiria não só o aborto de embriões em estágio inicial de desenvolvimento, mas também o aborto de fetos com todos as estruturas e órgãos já iniciados o desenvolvimento, e, até mesmo, com forma nitidamente humana.

Diante disso, em tempos de insegurança jurídica, faz-se necessário reafirmar que o termo inicial do delito de aborto continua sendo a nidação, até que o legislador opte por descriminalizar, após um rigoroso controle de convencionalidade e constitucionalidade, ou, ainda, adotar outro sistema de relativização da proteção da vida humana dependente, como por exemplo, o sistema de prazos, de forma isolada ou, ainda, combinada com o sistema de indicações.

\section{THE INITIAL TERM OF DEPENDENT HUMAN LIFE AND ITS PROTECTION IN THE CRIME OF ABORTION}

Abstract: The aim of the study was to delimit the initial term of the protection of dependent human life (objective type of the abortion offense) and for that purpose, the deductive and theoretical method was used, throughout the analysis of the jurisprudence and the bibliographical 
review of several periodicals, books, and papers published about the theme. In 2016, the First Panel of the Federal Supreme Court ruled Habeas Corpus number 124.306/2016, in which under an interpretation according to the Constitution, it considered atypical abortion practiced until the third month of gestation. In light of this, it can be said that the decision must be considered unconventional and also an appropriation by the Judiciary of items of jurisdiction and legitimacy of the Legislative Branch, violating the principle of separation of powers and legality in the criminal law.

Keywords: Dependent human life; Criminal jurisdiction; Abortion; Nidation; Judicial Review.

\section{REFERÊNCIAS}

ALMEIDA, Silmara J. A. Chinelato e. O nascituro no Código Civil e no direito constituendo do Brasil. Revista de Informação Legislativa, v. 25, n. 97, jan./mar. 1988.

BARROSO, Luís Roberto. A dignidade da pessoa humana no direito constitucional contemporâneo. A construção de um conceito jurídico à luz da jurisprudência Mundial. 3. ed. Belo Horizonte: Fórum, 2014.

BARROSO, Luís Roberto. Gestação de fetos anencefálicos e pesquisas com células tronco: dois temas acerca da vida e da dignidade na Constituição. Revista de Direito Administrativo, Rio de Janeiro, v. 241, p. 93-120, jul./set. 2005.

BATISTA, Nilo. Introdução crítica ao direito penal brasileiro. 11. ed. Rio de Janeiro: Revan, 2007.

BITENCOURT, Cezar Roberto. Tratado de Direito Penal. Parte especial. Dos crimes contra pessoa. 15. ed. São Paulo: Saraiva, 2015.

BOBBIO, Noberto. A era dos Direitos. Tradução Carlos Nelson Coutinho. Rio de Janeiro: Elsevier, 2004.

BONAVIDES, Paulo. Curso de Direito Constitucional. 15. ed. São Paulo: Malheiros, 2004.

BRASIL. Conselho Federal de Medicina. Resolução CFM no 1.989, de 14 de maio de 2012. Dispõe sobre o diagnóstico de anencefalia para a antecipação terapêutica do parto e dá outras providências. Diário Oficial da União, Brasília, 14 maio 2012.

Disponível: http://www.portalmedico.org.br/resolucoes/cfm/2012/1989_2012.pdf Acesso em: 06 jul. 2018.

BRASIL. Decreto No 678, de 6 de novembro de 1992. Promulga a Convenção Americana sobre Direitos Humanos (Pacto de São José da Costa Rica), de 22 de novembro de 1969. Diário Oficial da União, Brasília, 1992. Disponível em: http://www.planalto.gov.br/ccivil_03/decreto/d0678.htm. Acesso em: 06 jul. 2018.

BRASIL. Supremo Tribunal Federal. Anencefalia. Arguição de Descumprimento de Preceito Fundamental no 54 Distrito Federal. Voto do Min. Relator, Marco Aurélio. Plenário. 
Brasília-DF, 11 abr. 2012b. Disponível em:

http://www.stf.jus.br/arquivo/cms/noticianoticiastf/anexo/adpf54.pdf. Acesso em: 06 jul. 2018.

BRASIL. Supremo Tribunal Federal. Ação direta de inconstitucionalidade 3.510. Distrito Federal. Procurador geral da República e Presidente da República. Relator: Min. Carlos Ayres Britto. Acórdão não publicado. Brasília, 29 maio 2008. Disponível em:

http://redir.stf.jus.br/paginadorpub/paginador.jsp?docTP=AC\&docID=611723. Acesso em: 06 jul. 2018.

BRASIL. Código Civil. Lei 10.406, de 10 de janeiro de 2002. Brasília, 2002. Disponível em: http://www.planalto.gov.br/ccivil_03/leis/2002/110406.htm. Último acesso em: 06 de jul 2018.

BRASIL. Constituição Federal de 1988. Promulgada em 5 de outubro de 1988. Disponível em: http://www.planalto.gov.br/ccivil_03/constituicao/constituição.htm. Acesso em: 06 jul. 2018.

BRASIL. Supremo Tribunal Federal. Habeas Corpus n⿳ 124306/RJ - Rio de Janeiro. Relator: Ministro Marco Aurélio. Pesquisa de Jurisprudência, Data de Publicação Dje 17/03/2017 ATA No 31/2017. DJE n ${ }^{\circ}$ 52, divulgado em 16/03/2017. Disponível em: http://www.stf.jus.br/portal/processo/verProcessoAndamento.asp?incidente $=4637878$. Acesso em: 06 jul. 2018.

CARVALHO, Gisele Mendes de. Aspectos jurídico-penais da eutanásia. São Paulo: IBCCRIM, 2001.

CARVALHO, Gisele Mendes de. Curso de direito penal brasileiro. 3. ed. [e-boook]. São Paulo: Revista dos Tribunais, 2017. v. II. Parte especial.

CARVAlHO, Gisele Mendes de. Patrimônio genético \& Direito Penal. Curitiba: Juruá, 2007.

CASABONA, Carlos Maria Romeo. El derecho y la bioética ante los limites de la vida humana. Madrid: Editorial Centro de Estudios Ramón Areces, 1994.

CASABONA, Carlos María Romeu. El derecho a la vida: aspectos constitucionales de las nuevas biotecnologías. In: JORNADAS DE LA ASOCIACIÓN DE LETRADOS DEL TRIBUNAL CONSTITUCIONAL, 8., 2003, Madrid. Actas [...]. Madrid, 2003.

CIDH. Corte Interamericana de Direitos Humanos. Caso Artavia Murillo e Outros ("Fecundação in vitro") vs. Costa Rica. Sentença de 28 de novembro de 2012. Disponível em: http://www.corteidh.or.cr/docs/casos/articulos/seriec_257_por.pdf. Acesso em: 06 jul. 2018.

CIDH. Corte Interamericana de Direitos Humanos. Convenção Americana de Direitos Humanos. Assinada na Conferência Especializada Interamericana sobre Direitos Humanos, San José, Costa Rica, em 22 de novembro de 1969. Disponível em: $<$ https://www.cidh.oas.org/basicos/portugues/c.convencao_americana.htm>. Acesso em: 06 jul. 2018.

DINIZ, Maria Helena. Curso de Direito Civil Brasileiro. Teoria Geral do Direito Civil. 31. ed. São Paulo: Saraiva, 2014. 
FRAGOSO, Heleno Cláudio. Lições de Direito Penal. Parte Especial. 11. ed. Rio de Janeiro: Forense, 1995. v. I.

GONÇALVES, Diogo Costa. Pessoa e Direitos da Personalidade. Fundamentação Ontológica da Tutela. Coimbra: Edições Almedina, 2008.

HALBE, Hans Wolfgang; CUNHA, Donaldo Cerci da; RAMOS, Laudelino de Oliveira. Contracepção de urgência. Sinopse de Ginecologia e Obstetrícia [S.l.], v. 2, p. 31-37, 1998.

HUNGRIA, Nelson. Comentários ao Código Penal. Arts. 121 a 136. Rio de Janeiro: Forense, 1942. v. V.

MALANDA, Sergio Romeo. Intervenciones genéticas sobre el ser humano y derecho penal. Consideraciones político-criminales y consecuencias dogmáticas. Bilbão: Granada, 2006.

MARTINS, Ives Granda. A vida, o direito fundamental. Lex Humana, Rio de Janeiro, Petrópolis, v. 1, n. 1, 2009. Disponível em: http://hdl.handle.net/10316.2/33899. Acesso em: 06 jul. 2018.

MAZZUOLI, Valério de Oliveira. O controle jurisdicional da convencionalidade das leis. São Paulo: Revista dos Tribunais, 2016.

MOORE, Keith L.; PERSAUD, Mark G. Torchia. Embriologia Clínica. 10. ed. Rio de Janeiro: Elsevier, 2016.

PEREIRA, Caio Mario da Silva. Instituições do Direito Civil. 24. ed. Rio de Janeiro: Forense, 2011. v. I.

PRADO, Luiz Regis. Bem jurídico Penal e Constituição. 4. ed. São Paulo: Revista dos Tribunais, 2004.

PRADO, Luiz Regis. Curso de direito penal brasileiro. Parte especial. 6. ed. São Paulo: Revista dos Tribunais, 2007. v. 2.

PRADO, Luiz Regis; CARVALHO, Gisele Mendes de. Curso de direito penal brasileiro. 3. ed. [e-book], São Paulo: Revista dos Tribunais, 2017. v. II. Parte especial.

REZENDE, Jorge de. Obstetrícia. 9. ed. Rio de Janeiro: Guanabara Koogan, 2000.

ROXIN, Claus. A proteção de bens jurídicos como função do Direito Penal. Organização e Tradução André Luís Callegari. 2. ed. Porto Alegre: Livraria do Advogado, 2009.

SALEM, Tania. As novas tecnologias reprodutivas: o estatuto do embrião e a noção de pessoa. Mana, v. 3, n. 1, p. 75-94, 1997. Disponível em: http://www.scielo.br/pdf/mana/v3n1/2456.pdf. Acesso em: 02 jul. 2018.

SARLET, Ingo Wolfgang. Eficácia dos Direitos Fundamentais. Uma Teoria Geral dos Direitos Fundamentais na Perspectiva Constitucional. 12. ed. Porto Alegre: Livraria do Advogado, 2015. 
SARMENTO, Daniel. Direitos Fundamentais nas Relações Privadas. Rio de Janeiro: Lumen Juris, 2004.

WEZEL, Hans. O novo sistema jurídico-penal. Uma introdução à doutrina Finalista. Tradução Luiz Regis Prado. 2. ed. São Paulo: Revista dos Tribunais, 2009.

ZENNI, Alessandro Severino Váller; AIRES, Fernanda Diniz. RIBEIRO, Daniela Menengoti. A tutela do embrião in vitro na Convenção Americana de Direitos Humanos: uma interpretação da Corte Interamericana de Direitos Humanos. Revista Quaestio Iuris, Rio de Janeiro, v. 11, n. 2, p. 737-756, 2018. Disponível em: http://www.e-

publicacoes.uerj.br/index.php/quaestioiuris/issue/view/1785. Acesso em: 06 jul. 2018.

Trabalho enviado em 17 de janeiro de 2019

Aceito em 17 de março de 2019 